\title{
Assessment of the Effect of Silicon on Antioxidant Enzymes in Cotton Plants by Multivariate Analysis
}

\author{
Carlos Alberto Moldes, ${ }^{* \dagger}$ Oscar Fontão de Lima Filho, ${ }^{\ddagger}$ José Manuel Camiña, ${ }^{*}, \dagger, \S$ \\ Soraya Gabriela Kiriachek, ${ }^{\dagger}$ María Lia Molas," and Siu Mui Tsai ${ }^{\perp}$ \\ ${ }^{\dagger}$ Facultad de Ciencias Exactas y Naturales, Universidad Nacional de La Pampa, Av. Uruguay 151, CP 6300 Santa Rosa, La Pampa, \\ Argentina \\ ${ }^{\ddagger}$ Embrapa Agropecuaria Oeste, BR163 Km. 253, CEP 79804-970 Dourados, Mato Grosso do Sul, Brazil \\ ${ }^{\S}$ Instituto de las Ciencias de la Tierra y Ambientales de La Pampa (INCITAP), Av. Uruguay 151, CP 6300 Santa Rosa, La Pampa, \\ Argentina \\ "Facultad de Agronomía, Universidad Nacional de La Pampa, Ruta 35. Km. 334 CP 6300 Santa Rosa, La Pampa, Argentina \\ ${ }^{\perp}$ Centro de Energia Nuclear na Agricultura, Universidade de Sao Paulo, Av. Centernário 303, CEP 13400-970 Piracicaba, São Paulo, \\ Brazil
}

ABSTRACT: Silicon has been extensively researched in relation to the response of plants to biotic and abiotic stress, as an element triggering defense mechanisms which activate the antioxidant system. Furthermore, in some species, adding silicon to unstressed plants modifies the activity of certain antioxidant enzymes participating in detoxifying processes. Thus, in this study, we analyzed the activity of antioxidant enzymes in leaves and roots of unstressed cotton plants fertilized with silicon ( $\mathrm{Si}$ ). Cotton plants were grown in hydroponic culture and added with increasing doses of potassium silicate; then, the enzymatic activity of catalase (CAT), guaiacol peroxidase (GPOX), ascorbate peroxidase (APX), and lipid peroxidation were determined. Using multivariate analysis, we found that silicon altered the activity of GPOX, APX, and CAT in roots and leaves of unstressed cotton plants, whereas lipid peroxidation was not affected. The analysis of these four variables in concert showed a clear differentiation among Si treatments. We observed that enzymatic activities in leaves and roots changed as silicon concentration increased, to stabilize at 100 and $200 \mathrm{mg} \mathrm{Si} \mathrm{L}^{-1}$ treatments in leaves and roots, respectively. Those alterations would allow a new biochemical status that could be partially responsible for the beneficial effects of silicon. This study might contribute to adjust the silicon application doses for optimal fertilization, preventing potential toxic effects and unnecessary cost.

KEYWORDS: silicon, antioxidant enzymes, cotton, oxidative stress, multivariate analysis

\section{INTRODUCTION}

Essentiality and function of silicon in plant development has been largely discussed in plant nutrition literature. ${ }^{1}$ Silicon is absorbed and accumulates in concentrations that range from $1 \%$ to $10 \%$ of dry matter. This variability among plant species has been attributed to the ability of the roots to absorb $\mathrm{Si}^{2,3} \mathrm{Si}$ contributes to alleviate water stress because it reduces transpiration by developing a $\mathrm{Si}$ gel layer on the epidermal cell wall. ${ }^{4}$ In addition, the presence of silicon cell walls in fibers makes them hard and resistant, not only to water stress but also to pest and pathogens' attacks, increasing their tolerance to diseases. ${ }^{2}$ Therefore, the principal function of silicon in plants is to provide a "defense against environmental onslaughts, both biotic and abiotic". 5

Multivariate calibration methods are widely used to explain data relationships that are difficult to observe otherwise, being useful to identify hidden differences and to establish groups of data. ${ }^{6}$ For instance, cluster analysis (CA), discriminant analysis (DA), principal component analysis (PCA), factor analysis (FA), and partial-least-squares (PLS) modeling allowed the rapid analysis and interpretation of large complex data sets in environmental, chemical, biological, and ecotoxicological case studies. ${ }^{7}$ These methods have been successfully used to determine denomination of origin for honey ${ }^{8}$ and wines, ${ }^{9}$ quality of edible oils, ${ }^{10}$ genotype classification, ${ }^{11,12}$ and varieties of fruits. ${ }^{13}$ More recently, multivariate tools were successfully used for the classification of propolis samples ${ }^{14}$ and South American herbs. ${ }^{15}$

A few reports were found, applying chemometrics to biological systems in order to analyze biochemical parameters in plants. In iron-exposed plants, chemometric approaches revealed a pattern of variation in the biochemical responses that could not be observed through univariate statistics. ${ }^{7}$ DiazJaramillo et al. ${ }^{16}$ studied GST, GSH activity, and total antioxidant capacity in Perinereis gualpensis. Using multivariate analysis, they grouped different sites exposed to contamination in Chile, suggesting their potential use as biomarkers; Larrigaudière et al. ${ }^{17}$ analyzed the role of antioxidant and fermentative metabolisms to determine if core browning and brown heart in pears (Pirus communis) are associated with the same disorder. Using principal component analysis, they studied antioxidant enzymes (i.e., catalase, ascorbate peroxidase, glutathione reductase, and superoxide dismutase activity),

Received: May 23, 2013

Revised: October 31, 2013

Accepted: November 4, 2013

Published: November 4, 2013 
fermentative variables (pyruvate decarboxylase and alcohol dehydrogenase activity), and lipoxigenases activity, and they found that both postharvest disorders involve different metabolic pathways.

Cotton (Gossypium hirsutum) is a nonsilicon accumulator ${ }^{18}$ and, as such, may be useful to study the biochemical effect of stress alleviation by silicon application. It has been reported that $\mathrm{Si}$ helped to mitigate aluminum toxicity ${ }^{19}$ and to control the damage produced by insects in cotton; ${ }^{20,21}$ however, the activity of antioxidant enzymes under silicon treatment has not been reported.

Si has been proved to trigger plant defense mechanisms as an activator of strategic signaling proteins. ${ }^{22}$ Addition of $\mathrm{Si}$ to plants under stress decreases the oxidative damage by diminishing the levels of hydrogen peroxide, lipid peroxidation, or electrolytic leakage in several species such as soybean, ${ }^{23}$ Chinese cabbage, ${ }^{24}$ grapevine, ${ }^{25}$ maize, ${ }^{26}$ cucumber, ${ }^{27,28}$ wheat, ${ }^{29,30}$ tomato, ${ }^{31}$ and barley. ${ }^{32}$ In these studies, several authors reported that the activity of several enzymes such as superoxide dismutase, catalase, and peroxidases were divergent.

In addition, $\mathrm{Si}$ application affects the gene expression profile in plants. Under stress, addition of silicon induces a significant increase in the transcription of genes involved in the defense response of several plant species such as rice, ${ }^{33,34}$ Arabidopsis thaliana, ${ }^{22}$ tomato, ${ }^{35}$ and wheat. ${ }^{36}$ In the same studies, addition of silicon to plants under unstressed conditions has no significant modification in the transcriptomic profile. This fact suggests that Silicon has a latent role in nonstressed plants, and its effect is not evident until a stressful situation occurs.

On the other hand, at a transductional level, silicon treatments modified the activity of antioxidant enzymes in unstressed plants. ${ }^{24,28-31}$ Several studies investigating the effect of $\mathrm{Si}$ on stressed plants also revealed that $\mathrm{Si}$ alters the metabolism in antioxidant activities. In the case of Brassica chinensis, it was observed that SOD, CAT, and APX increased in controls added with silicon. ${ }^{24}$ In cucumber, an increase of APX was observed after silicon addition to the control plants, but no alteration was observed in CAT and GR. ${ }^{28}$ Besides, a decrease in GPOX activity took place in tomato plants supplemented with silicon. $^{31}$

Since the induction/inhibition of antioxidant enzymes is one of the first defense responses under stress, it is important to analyze whether silicon intervenes in the antioxidant metabolism in order to adjust the plant fitness for a potential defense response. In this regard, the use of multivariate analysis provides a complementary approach to understand the effect of $\mathrm{Si}$ on plants, since a variable reduction could offer hidden information, which is not noticeable using traditional univariate statistical analysis.

On this basis, the aim of this study was to evaluate the effect of silicon on antioxidant enzyme activities (i.e., catalase, ascorbate peroxidase, and guaiacol peroxidase) of unstressed cotton plants using multivariate analysis with the purpose of establishing whether there are patterns of antioxidant enzyme behavior that may help understand the benefits of silicon on plants.

\section{MATERIALS AND METHODS}

Cotton seeds of "CEDRO" cultivar were acquired from Agencia Paulista de Tecnologia dos Agronegócios, Instituto Agronômico de Campinas. The seeds were superficially sterilized with hypochlorite solution (2\%), rinsed with water, and placed in mini spots with a sand-vermiculite $(2: 1)$ mixture. Seven to ten days after, germination seedlings with similar heights were selected and transferred to $2 \mathrm{~L}$ plastic pots containing a 5-fold diluted Hoagland and Arnon ${ }^{37}$ nutrient solution at $\mathrm{pH}$ 7. The seedlings were adapted during 7 days to liquid nutrient media. Then, diluted nutrient media were replaced by a complete nutrient solution. Two seedlings per pot were grown in a glasshouse at $25{ }^{\circ} \mathrm{C}$ and $45 \%$ humidity. When plants reached 90 days in the nutrient solution, a soluble silicate such as $\mathrm{K}_{2} \mathrm{SiO}_{3}$ (Unaprosil, Rio de Janeiro) was added in concentrations ranging from $0,25,50$, 100 , to $200 \mathrm{mg} \mathrm{Si} \mathrm{L}{ }^{-1}$. Potassium concentration was maintained at the level of the Hoagland \& Arnon nutrient solution (0.003 M), proportionally decreasing the concentration of potassium nitrate with each Si treatment. On the other hand, nitrogen concentration was compensated by proportionally adding ammonium nitrate. Treatment solutions were made at $\mathrm{pH} 7$ and replaced weekly. Samples of leaves and roots from 120 day plants were transplanted and later collected in liquid nitrogen and stored in the ultrafreezer at $-80{ }^{\circ} \mathrm{C}$. Experiments were carried out in a completely randomized design with five replications for each silicon treatment.

Lipid peroxidation was determined by measuring the malondialdehyde (MDA) content, as previously described. ${ }^{38}$ Leaves and roots (250 mg fresh weight) were crushed and homogenized in a mortar with $20 \%(\mathrm{w} / \mathrm{v})$ insoluble polyvinylpyrrolidone (PVPP) and $1.3 \mathrm{~mL}$ of $0.1 \%$ trichloroacetic acid (TCA) solution. The homogenate was centrifuged at $10000 \mathrm{rpm}$ for $5 \mathrm{~min}$, and $250 \mu \mathrm{L}$ of the supernatant was added to $1 \mathrm{~mL}$ of $0.5 \%$ 2-thiobarbituric acid (TBA) and 20\% TCA solution, and incubated in a water bath at $95{ }^{\circ} \mathrm{C}$ for $20 \mathrm{~min}$. The concentration of MDA was calculated from the absorbance at $532 \mathrm{~nm}$, using the absorbance coefficient $155 \mathrm{mM}^{-1} \mathrm{~cm}^{-1}$, following a correction for unspecific turbidity determined by the absorbance at $600 \mathrm{~nm}$.

Enzyme extracts were obtained from cotton leaves and roots crushed and homogenized in a mortar with $100 \mathrm{mM}$ potassium phosphate buffer ( $\mathrm{pH} 7.5)$ containing $1 \mathrm{mM}$ ethylene diaminetetracetic acid (EDTA), $3 \mathrm{mM}$ DL-dithiothreitol, and $5 \%(\mathrm{w} / \mathrm{v})$ insoluble PVPP. The homogenate was centrifuged at $10000 \mathrm{rpm}$ for $30 \mathrm{~min}$, and the supernatant was stored in separate aliquots at $-80{ }^{\circ} \mathrm{C}$ for the determination of enzyme activity. ${ }^{38}$

Catalase (CAT-EC 1.11.1.6) activity was studied at $25^{\circ} \mathrm{C}$ in a $1 \mathrm{~mL}$ eppendorff tube containing $100 \mathrm{mM}$ potassium phosphate buffer $(\mathrm{pH}$ 7.5 ) and $0.0075 \% \mathrm{H}_{2} \mathrm{O}_{2}$. The reaction was initiated by the addition of 20-40 $\mu \mathrm{L}$ of plant extract and determined by monitoring $\mathrm{H}_{2} \mathrm{O}_{2}$ degradation in the spectrophotometer at $240 \mathrm{~nm}$ over 1 min. $^{39}$ CAT activity was calculated using an extinction coefficient of $39.4 \mathrm{mM}^{-1}$ $\mathrm{cm}^{-1}$ for $\mathrm{H}_{2} \mathrm{O}_{2}$, and it was expressed in $\mathrm{nmol} \mathrm{H}_{2} \mathrm{O}_{2} \mathrm{~min}^{-1} \mathrm{mg}$ protein $^{-1}$.

Guaiacol peroxidase (GPOX, EC 1.11.1.7) activity was measured in a $1 \mathrm{~mL}$ mixture reaction containing $0.2 \mathrm{M}$ potassium phosphate-0.1 $\mathrm{M}$ sodium citrate buffer ( $\mathrm{pH} 5.0$ ), $0.01 \%$ guaiacol, and $0.06 \% \mathrm{H}_{2} \mathrm{O}_{2}$. The reaction was initiated by the addition of $5-10 \mu \mathrm{L}$ of plant extract and incubated at $30{ }^{\circ} \mathrm{C}$ for $15 \mathrm{~min}$. The reaction was stopped by rapid cooling in an ice water bath and the addition of $20 \mu \mathrm{L}$ of sodium metabisulphite $0.2 \%(\mathrm{w} / \mathrm{v})$. After vortex, the reaction was kept for 10 min and the GPOX activity was determined by absorbance at $450 \mathrm{~nm}$, and quantified according to Gomes-Junior et al. ${ }^{39}$ GPOX activity was expressed in per milligram of protein.

Ascorbate peroxidase activity (APX, EC 1.11.1.11) was determined by monitoring the rate of ascorbate oxidation at $290 \mathrm{~nm}$ at $30{ }^{\circ} \mathrm{C}$. The reaction was initiated by the addition of $40 \mu \mathrm{L}$ of plant extract to $1 \mathrm{~mL}$ of a medium containing $50 \mathrm{mM}$ potassium phosphate buffer ( $\mathrm{pH} 7.0$ ), $0.5 \mathrm{mM}$ ascorbate, $0.1 \mathrm{mM}$ EDTA, and $0.1 \mathrm{mM} \mathrm{H} \mathrm{H}_{2} \mathrm{O}_{2}$. APX activity, expressed as nanomoles of ascorbate per minute milligrams of protein, was calculated using the extinction coefficient $2.8 \mathrm{mM}^{-1} \mathrm{~cm}^{-1}$ for ascorbate. $^{40}$

The protein concentration was determined by the method of Bradford $^{41}$ using bovine serum albumin (BSA) as a standard.

ANOVA (significant differences of $p<0.05$ ) and linear regression analysis (significant regression of $p<0.05$ ) was performed by SAS statistical program (SAS Institute Inc., Cary, NC, 1999), and principal component analysis (PCA) for multivariate analysis was performed using the Unscrumbler 6.11 package (CAMO AS, Norway). 


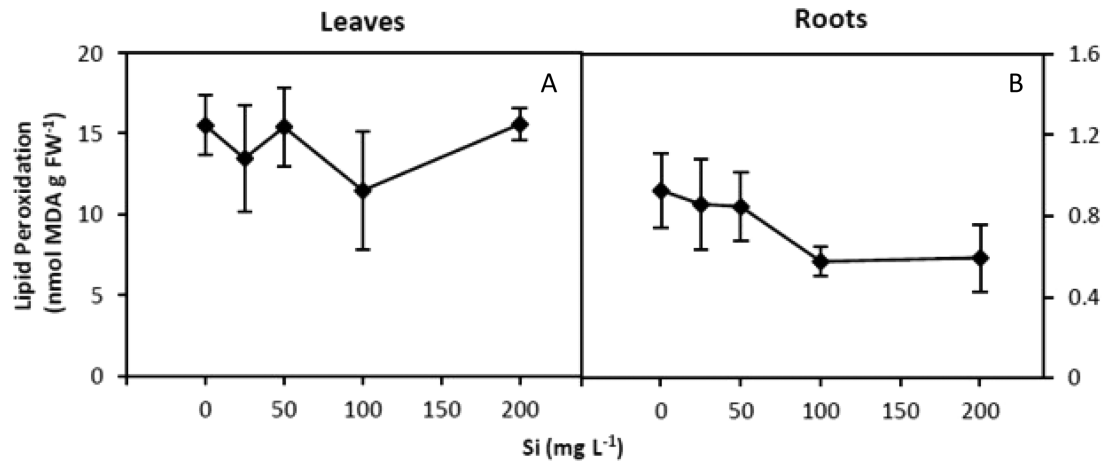

Figure 1. Effect of increasing silicon concentration on lipid peroxidation in leaves and roots of cotton plants. Bars represent the standard deviation of each mean, $n=5$.

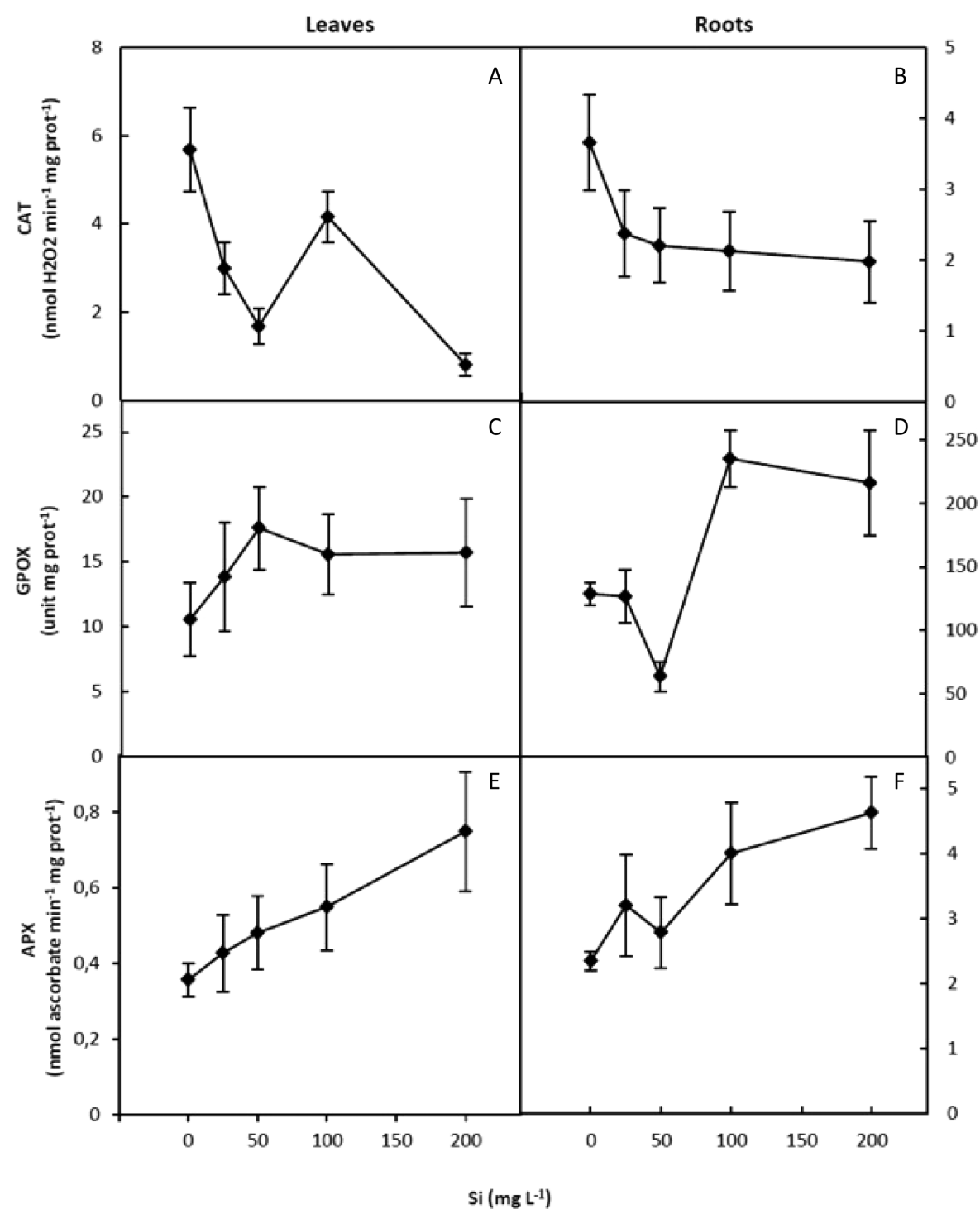

Figure 2. Effect of increasing silicon concentration on CAT, GPOX, and APX specific activity in leaves and roots of cotton plants. Bars represent the standard deviation of each mean, $n=5$.

\section{RESULTS}

Lipid Peroxidation Analysis and CAT, APX, and GPOX Enzymatic Activity. Lipid peroxidation was measured by malondialdehyde contents in leaves and roots' extracts and analyzed by ANOVA and linear regression. Addition of silicon in the range of 0 to $200 \mathrm{mg} \mathrm{L}^{-1}$ did not alter lipid peroxidation in leaves (Figure 1A; ANOVA: $p=0.0891$; Linear regression: $r$ $=0.0100, p=0.9548)$; however, in roots, lipid peroxidation decreased in treatments of 100 and $200 \mathrm{mg} \mathrm{L}^{-1}$, showing a decrease trend as silicon treatment increased (Figure 1B; ANOVA: $p=0.0089$; linear regression: $r=-0.6016, p=$ 


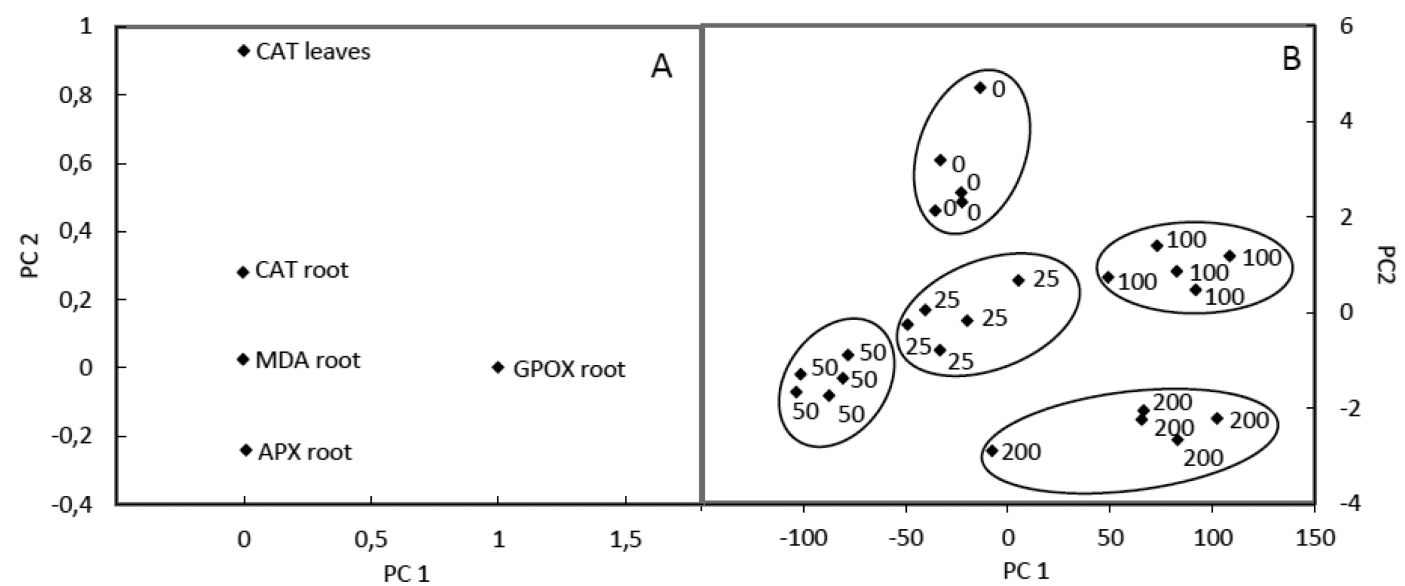

Figure 3. (A) Loading plot showing the influence of lipid peroxidation (MDA), CAT, APX, and GPOX variables measured in roots and the CAT variable measured in leaves, in the PCA model. (B) Scores plot shows the discrimination of Si treatments.

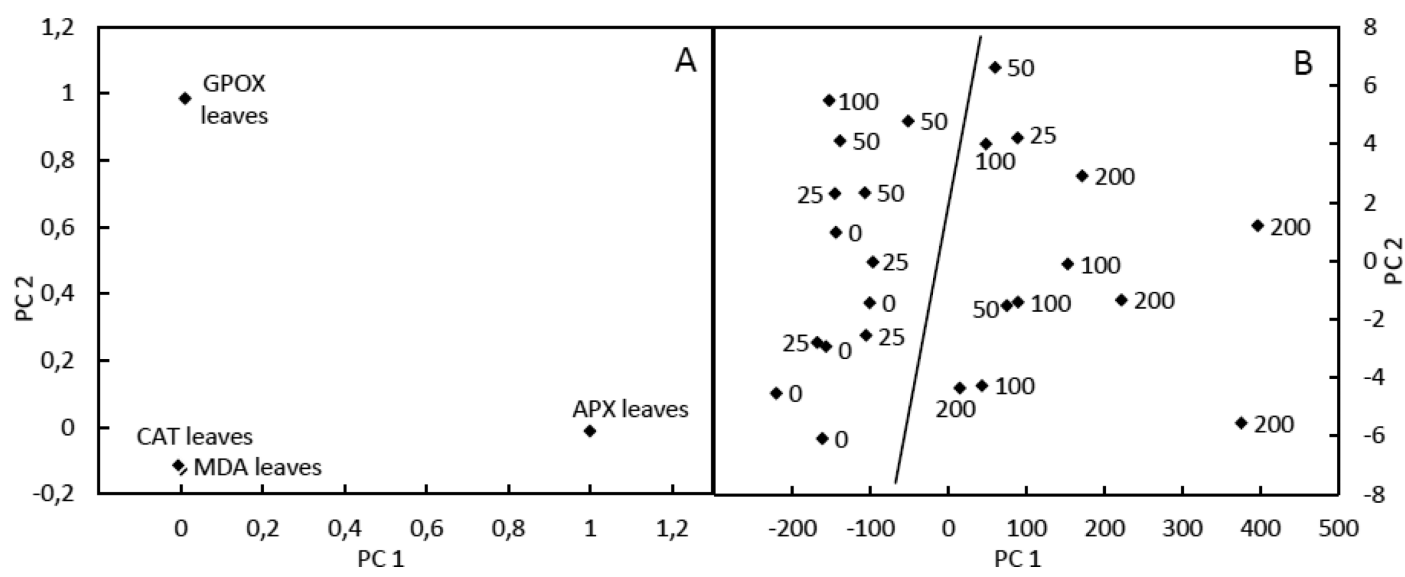

Figure 4. Loading plot showing the influence of the leaves variables in the PCA model. Discrimination obtained in the (B) Scores plot for every Si treatment.

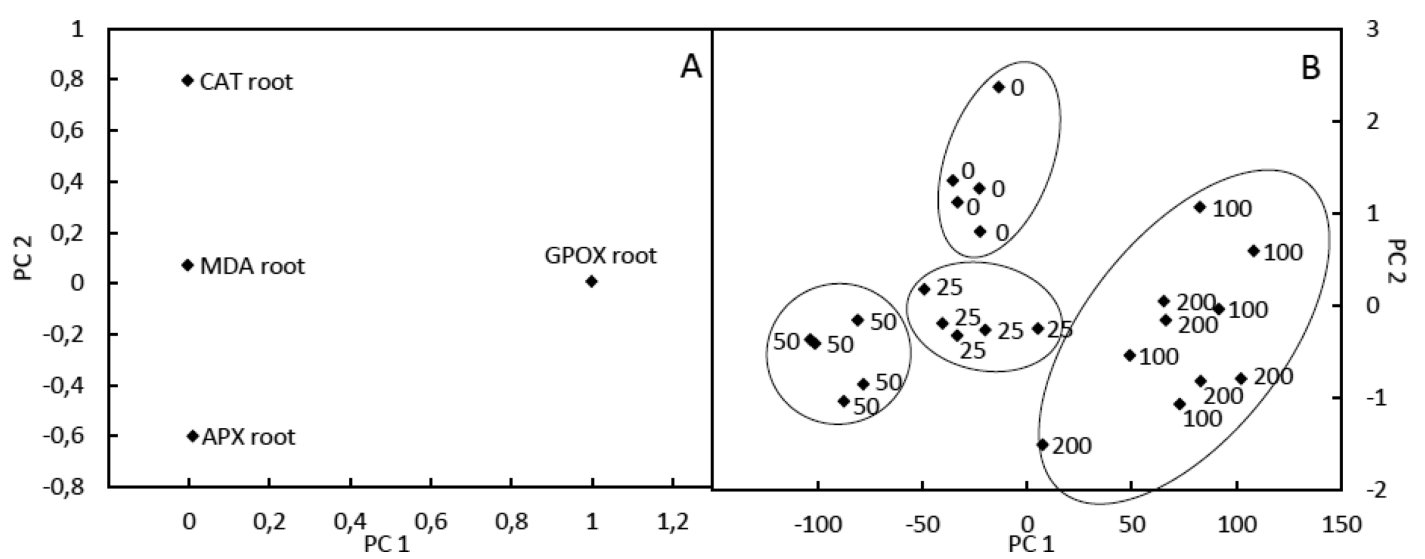

Figure 5. (A) Loading plot showing the influence of the roots variables for discrimination of Si treatments expressed in the (B) Score plot.

$0.0015)$. Catalase activity diminished in leaves as well as roots when $\mathrm{Si}$ increased in the nutrient solution (Figure 2A; ANOVA: $p<0.0001$; linear regression: $r=-0.6427, p=$ 0.0005; and Figure 2B; ANOVA: $p=0.0014$; linear regression: $r=-0.5201, p=0.0077)$. GPOX in leaves have no significant differences among treatments (Figure 2C; ANOVA: $p=$ 0.0551; linear regression: $r=0.3044, p=0.1389$ ), while GPOX activity in roots (Figure 2D; ANOVA: $p<0.0001$; linear regression: $r=0.6486, p=0.0005)$ and APX activity in both leaves and roots (Figure 2E; ANOVA: $p=0.0002$; linear regression: $r=0.8064, p<0.0001$, and Figure 2F; ANOVA: $p<$ 0.0001; linear regression: $r=0.7822, p<0.0001$ ) show an opposite tendency compared to that of CAT in both tissues.

Chemometrics. Multivariate analysis was performed in order to find a pattern describing changes in metabolism of cotton plants after addition of Si. The MDA content and CAT, APX and GPOX activity of roots, and CAT of leaves were analyzed by principal component analysis (PCA) to evaluate 
the grouping of samples in five Si concentrations $(0,25,50$, 100 , and $\left.200 \mathrm{mg} \mathrm{L}^{-1}\right)$. In the loading plot analysis, Figure $3 \mathrm{~A}$ shows that GPOX root and CAT leaves (onto PC1 and PC 2, respectively) were the most important variables for grouping $\mathrm{Si}$ treatments. The scores plot (Figure $3 \mathrm{~B}$ ) indicates that principal component 2 (PC2) better discriminates the silicon treatments of 0,50 , and $200 \mathrm{mg} \mathrm{L}^{-1}$ application. On the other hand, principal component 1 ( $\mathrm{PC} 1$ ) adjusts better to treatments of 25, 50, and $100 \mathrm{mg} \mathrm{L}^{-1}$ of Si. This model, based on four variables of roots and one of leaves, suggests that the parameters measured in roots are more precise to evaluate changes induced by silicon. For this reason, multivariate analysis of variables measured in roots and leaves was performed separately.

The loading plot for leaves variables (Figure 4A) indicated that APX leaves and GPOX leaves were the most significant variables in the first and second principal components, respectively. Treatments with high $\mathrm{Si}$ concentration were discriminated by influence of the APX leaves variable. Although the scores plot (Figure 4B) showed an important dispersion among the samples, a partition between the treatments 100 and $200 \mathrm{mg} \mathrm{L}^{-1}$ of $\mathrm{Si}$ and the rest of the treatments was still observed.

The loading plot for root variables (Figure 5A) indicates that the GPOX root variable in the first group and CAT root and APX root in the second one were three principal variables determining each group. The $0 \mathrm{mg} \mathrm{L}^{-1} \mathrm{Si}$ treatment was discriminated from the rest of the treatments due to the influence of the CAT root and APX root variables, while the GPOX root grouped high silicon concentrations (100 and 200 $\mathrm{mg} \mathrm{L}^{-1} \mathrm{Si}$ ). The scores plot (Figure 5B) showed an accurate division among treatments, except for 100 and $200 \mathrm{mg} \mathrm{L}^{-1} \mathrm{Si}$, which share the same group. These analyses provide a better grouping of treatments in roots in comparison with those of leaves.

\section{DISCUSSION}

In this study using multivariate analysis, we found that silicon alters the activity of GPOX, APX, and CAT in roots and leaves of unstressed cotton plants, while lipid peroxidation is not affected in leaves and decrease slightly in roots. The analysis of these variables in concert showed a clear differentiation among Si treatments, especially in roots. The studied variables showed a pattern of distribution in which four groups were detected (Figure 5B). However, these results were more difficult to observe using univariate statistics (Figures 1 and 2). Sinha et al. ${ }^{7}$ underlined the difficulty in the analysis and interpretation of induced oxidative stress and biochemical changes due to the complex nature of biochemical responses and their interrelationships.

Antioxidant response to silicon application varies with plant species and often with cultivars of the same species. ${ }^{24,42,43}$ If we compare the $\mathrm{Si}$ treatment with untreated controls, the antioxidant response does not always correlate with an increase of antioxidant enzyme activities. Results in our study showed a decrease in CAT activity both in leaves and roots. Wang et al. ${ }^{42}$ report that silicon decreases GPOX activity in shoots and SOD activity in leaves of alfalfa. In leaves of soybean, SOD, CAT, and GPOX have no significant differences after silicon treatments. ${ }^{23}$ Similar results were obtained in leaves of cucumber ${ }^{28}$ and tomato. $^{31}$

On the other hand, our work showed an increase in APX and GPOX activity, both in leaves and roots. Similar results were found by Liu et al. ${ }^{44}$ showing significant increase of SOD, CAT, GPOX, and APX in leaves' extracts of cucumber. Feng et al. ${ }^{45}$ found an increase in APX of cucumber leaves, while the same trend was reported by Song et al. ${ }^{24}$ in leaves of two cultivars of Brassica chinensis treated with silicon in hydroponic solution. In Seashore paspalum turfgrass, silicon clearly induced the CAT activity in leaves. ${ }^{46}$ Two peanut cultivars showed an increase in SOD, CAT, and GPOX activities in leaves and roots. ${ }^{43}$ Overall, there is abundant literature reporting major alterations in antioxidant response when plants are exposed to silicon.

The multivariate analysis performed in this study allowed us to observe changes in enzymatic activities of leaves and roots as the silicon concentration increased to stabilize at 100 and 200 mg Si L ${ }^{-1}$ treatments. Gunes et $\mathrm{al}^{47}$ report a decrease of SOD and CAT activity and the increase of APX in barley shoots when plants were grown in a hydroponic solution added with silicon. They also found significant changes in antioxidant enzyme activity between 0 and $70 \mathrm{mg} \mathrm{Si} \mathrm{kg}{ }^{-1}$. Activities in 70, 140 , and $280 \mathrm{mg} \mathrm{Si} \mathrm{kg}{ }^{-1}$ were similar, resembling a plateau in concentrations over $70 \mathrm{mg} \mathrm{Si} \mathrm{kg}{ }^{-1}$. Thus, results using multivariate statistical analysis clearly showed changes in the antioxidant metabolism that run parallel to increasing silicon doses, reaching a point where additional Si has no effect on the antioxidant activity (Figures 4 and 5 ).

Studies based on broad spectrum transcriptomic analysis (microarrays) have reported that few genes are differentially expressed when $\mathrm{Si}$ is added to unstressed plants. Fauteux et al. ${ }^{22}$ studied the Arabidopsis-powdery mildew pathosystem at the transcriptional level and found only two genes (out of 40000 transcripts present on the microarray chip) differentially expressed in healthy plants exposed to silicon. Khandekar and Leisner ${ }^{48}$ in their study of Arabidopsis thaliana did not observe any significant alteration in transcripts CSD1, CSD2 (copper/ zinc superoxide dismutases) and GST24 (glutathione-S-transferase) in silicon treatments compared to nontreated controls. They concluded that silicon has no noticeable effect, inducing gene expression in unstressed plants growing in the presence of silicon. Similar results were obtained in rice by Watanabe et al., and ${ }^{33}$ Brunnings et al., ${ }^{34}$ on their part, observed that silicon treatment in rice induces the upregulation of two transcripts of peroxidase precursors but downregulated the expression of a peroxidase gene. In plants of wheat supplemented with $\mathrm{Si}$, Chain et al. ${ }^{36}$ observed that four stress-response genes and one defense response gene were differentially expressed.

Even though some species do not seem to respond to silicon at a transcriptional level, there is some evidence showing a regulation at the level of protein activity, such as the alteration of antioxidant activity discussed earlier in this text. Besides, silicon effects could involve changes at other biochemical levels such as protein transduction, protein structure, or transport across membranes. ${ }^{49,50}$ Studies about the destiny and transformation of soluble silicates into the plant could provide answers on the benefits of silicon nutrition.

Summarizing, our study showed that the activity of several antioxidant enzymes can be altered after $\mathrm{Si}$ addition to unstressed plants. The analysis of antioxidant parameters using multivariate tools showed that silicon, in the absence of stress, induced alterations in antioxidant activities in leaves and roots of cotton plants. These alterations, in turn, induced a new biochemical status which, applying multivariate analysis became noticeable; however, these differences were less evident when classical univariate statistical methods where applied. Such effects are likely due to the unknown influence of silicon on 
biochemical and/or physiological processes. In addition, chemometrics of antioxidant enzymes activity could be a promising tool for the adjustment of silicon application doses for optimal fertilization, preventing excessive doses, unnecessary economic costs, and potentially eco-toxic effects.

\section{AUTHOR INFORMATION}

\section{Corresponding Authors}

*E-mail 1: moldesc@gmail.com. Tel: +54-2954-436787. Fax: +54-2954-432535.

*E-mail 2: jcaminia@gmail.com. Tel: +54-2954-436787+542954-245220/30 int. 7433. Fax: +54-2954-432535.

\section{Notes}

The authors declare no competing financial interest.

\section{ACKNOWLEDGMENTS}

This work was funded by the Conselho Nacional de Desenvolvimento Científico e Tecnológico (CNPq, Grant no. 309760/2003-8), Brazil. We would like to thank Prof. Roberto Olsina (Universidad Nacional de San Luis, Argentina) for providing The Unscrambler 6.11 software. We are also grateful for research grants from Consejo Nacional de Investigaciones Cientificas y Técnicas (CONICET), Agencia Nacional de Promoción Científica y Tecnológica (ANPCYT) and Universidad Nacional de La Pampa, Argentina that supported this research.

\section{REFERENCES}

(1) Epstein, E. Silicon. Annu. Rev. Plant Biol. 1999, 50, 641-664.

(2) Epstein, E. The anomaly of silicon in plant biology. Proc. Natl. Acad. Sci. U.S.A. 1994, 91, 11-17.

(3) Parveen, A.; Hussain, F. Salinity tolerance of three range grasses at germination and early growth stages. Pak. J. Bot. 2008, 40, 24372441.

(4) Sacala, E. Role of silicon in plant resistance to water stress. Journal of Elementology 2009, 14, 619-630.

(5) Epstein, E. Silicon: Its manifold roles in plants. Ann. Appl. Biol. 2009, 155, 155-160.

(6) Mongay Fernandez, C. Quimiometría; Publicaciones Universidad de Valencia: Valencia, Spain, 2005; pp 247-280.

(7) Sinha, S.; Basant, A.; Malik, A.; Singh, K. P. Iron-induced oxidative stress in a macrophyte: A chemometric approach. Ecotoxicol. Environ. Saf. 2009, 72, 585-595.

(8) Camiña, J. M.; Cantarelli, M. A.; Lozano, V. A.; Boeris, M. S.; Irimia, M. E.; Gil, R. A.; Marchevsky, E. J. Chemometric tools for the characterization of honey produced in La Pampa, Argentina from their elemental content, using inductively coupled plasma optical emission spectrometry (ICP-OES). J. Apic. Res. 2008, 47, 102-107.

(9) Di Paola-Naranjo, R. D.; Baroni, M. V.; Podio, N. S.; Rubinstein, H. R.; Fabani, M. P.; Badini, R. G.; Inga, M.; Ostera, H. A.; Cagnoni, M.; Gallegos, E.; Gautier, E.; Peral-García, P.; Hoogewerff, J.; Wunderlin, D. A. Fingerprints for main varieties of argentinean wines: Terroir differentiation by inorganic, organic, and stable isotopic analyses coupled to chemometrics. J. Agric. Food Chem. 2011, 59, 7854-7865.

(10) Cantarelli, M. A.; Funes, I. G.; Marchevsky, E. J.; Camiña, J. M. Determination of oleic acid in sunflower seeds by infrared spectroscopy and multivariate calibration method. Talanta 2009, 80, 489-492.

(11) Pereyra-Irujoa, G. A.; Izquierdo, N. G.; Covi, M.; Nolasco, S. M.; Quiroz, F.; Aguirrezábal, L. A. N. Variability in sunflower oil quality for biodiesel production: A simulation study. Biomass Bioenergy 2009, 33, 459-468.

(12) Moldes, C. A.; Camiña, J. M.; Medici, L. O.; Tsai, S. M.; Azevedo, R. A. Physiological effects of glyphosate over amino acid profile in conventional and transgenic soybean (Glycine max). Pestic. Biochem. Physiol. 2012, 102, 134-141.
(13) Ranalli, A.; Pollastri, L.; Contento, S.; Di Loreto, G.; Iannucci, E.; Lucera, L.; Russi, F. Acylglycerol and fatty acid components of pulp, seed, and whole olive fruit oils. Their use to characterize fruit variety by chemometrics. J. Agric. Food Chem. 2002, 50, 3775-3779.

(14) Cantarelli, M. A.; Camiña, J. M.; Pettenati, E.; Marchevsky, E. J.; Pellerano, P. G. Trace mineral content of Argentinean raw propolis by neutronic activation analysis (NAA): Assessment of geographical provenance by chemometrics. LWT-Food Sci. Technol. 2011, 44, $256-260$.

(15) Cantarelli, M. A.; Pellerano, R. G.; Del Vitto, L. A.; Marchevsky, E. J.; Camiña, J. M. Characterization of two South American food plants based on their multielemental composition. Phytochem. Anal. 2010, 21, 550-555.

(16) Díaz-Jaramillo, M.; Ferreira, J. L.; Amado, L. L.; Ventura-Lima, J.; Martins, A.; Retamal, M. R.; Urrutia, R.; Bertránd, C.; Barra, R; Monserrat, J. M. Biomonitoring of antioxidant and oxidative stress responses in Perinereis gualpensis (Polychaeta: Nereididae) in Chilean estuarine regions under different anthropogenic pressure. Ecotoxicol. Environ. Saf. 2010, 73, 515-523.

(17) Larrigaudière, C.; Lentheric, I.; Puy, J.; Pintó, E. Biochemical characterisation of core browning and brown heart disorders in pear by multivariate analysis. Postharvest Biol. Technol. 2004, 31, 29-39.

(18) Nishimura, K.; Miyaki, Y.; Takahashi, E. On silicon, aluminium, and zinc accumulators discriminated from 147 species of Angiospermae. Mem. Coll. Agric., Kyoto Univ. 1989, 133, 23-43.

(19) Li, Y. C.; Adva, A. K.; Sumner, M. E. Response of cotton cultivars to aluminum in solutions with varying silicon concentrations. J. Plant Nutr. 1989, 12, 881-92.

(20) Alcantra, E.; Moraes, J. C.; Antonio, A. Effect of inducers of resistance and cultivars of cotton on the behavior of Aphis gossypii. Rev. Cienc. Agron. 2010, 41, 619-624.

(21) Alcantra, E.; Moraes, J. C.; Antonio, A.; Alvarenga, R.; Françoso, $\mathrm{J}$. Effect of silicon and acibenzolar-s-methyl on colored cotton plants infested or not with Aphis gossypii Glover (Hemiptera, Aphididae). Revista Brasileira de Entomologia 2011, 55, 279-282.

(22) Fauteux, F.; Chain, F.; Belzile, F.; Menzies, J. G.; Bélanger, R. R. The protective role of silicon in the Arabidopsis-powdery mildew pathosystem. Proc. Natl. Acad. Sci. U.S.A. 2006, 103, 17554-17559.

(23) Shen, X.; Zhou, Y.; Duan, L.; Li, Z.; Eneji, A. E.; Li, J. Silicon effects on photosynthesis and antioxidant parameters of soybean seedlings under drought and ultraviolet-B radiation. J. Plant Physiol. 2010, 167, 1248-1252.

(24) Song, A.; Li, Z.; Zhang, J.; Xue, G.; Fan, F.; Liang, Y. Siliconenhanced resistance to cadmium toxicity in Brassica chinensis L. is attributed to Si-suppressed cadmium uptake and transport and Sienhanced antioxidant defense capacity. J. Hazard Mater. 2009, 172, 74-83.

(25) Soylemezoglu, G.; Demir, K.; Inal, A.; Gunes, A. Effect of silicon on antioxidant and stomatal response of two grapevine (Vitis vinifera L.) rootstocks grown in boron toxic, saline and boron toxic-saline soil. Sci. Hortic. 2009, 123, 240-246.

(26) Kaya, C.; Tuna, L.; Higgs, D. Effect of silicon on plant growth and mineral nutrition of maize grown under water-stress conditions. J. Plant Nutr. 2006, 29, 1469-1480.

(27) Shi, Q.; Bao, Z.; Zhu, Z.; He, Y.; Qian, Q.; Yu, J. Siliconmediated alleviation of $\mathrm{Mn}$ toxicity in Cucumis sativus in relation to activities of superoxide dismutase and ascorbate peroxidase. Phytochemistry 2005, 66, 1551-1559.

(28) Zhu, Z.; Wei, G.; Li, J.; Qian, Q.; Yu, J. Silicon alleviates salt stress and increases antioxidant enzymes activity in leaves of saltstressed cucumber (Cucumis sativus L.). Plant Sci. 2004, 167, 527-533.

(29) Gunes, A.; Inal, A.; Bagci, E. G.; Coban, S.; Sahin, O. Silicon increases boron tolerance and reduces oxidative damage of wheat grown in soil with excess boron. Biol. Plant. 2007, 51, 571-574.

(30) Gong, H. J.; Chen, K. M.; Zhao, Z. G.; Chen, G. C.; Zhou, W. J. Effects of silicon on defense of wheat against oxidative stress under drought at different developmental stages. Biol. Plant. 2008, 52, 592596. 
(31) Al-aghabary, K.; Zhu, Z.; Shi, Q. Influence of silicon supply on chlorophyll content, chlorophyll fluorescence, and antioxidative enzyme activities in tomato plants under salt stress. J. Plant. Nutr. 2004, 27, 2101-2115.

(32) Liang, Y.; Chen, Q.; Liu, Q.; Zhang, W.; Ding, R. Exogenous silicon $(\mathrm{Si})$ increases antioxidant enzyme activity and reduces lipid peroxidation in roots of salt-stressed barley (Hordeum vulgare L.). J. Plant Physiol. 2003, 160, 1157-1164.

(33) Watanabe, S.; Shimoi, E.; Ohkama, N.; Hayashi, H.; Yoneyama, T.; Yazaki, J.; Fujii, F.; Fujiwara, T. Identification of several rice genes regulated by Si nutrition. Soil Sci. Plant Nutr. 2004, 50, 1273-1276.

(34) Brunings, A. M.; Datnoff, L. E.; Ma, J. F.; Mitani, N.; Nagamura, Y.; Rathinasabapathi, B.; Kirst, M. Differential gene expression of rice in response to silicon and rice blast fungus Magnaporthe oryzae. Ann. Appl. Biol. 2009, 155, 161-170.

(35) Ghareeb, H.; Bozsó, Z.; Ott, P. G.; Repenning, C.; Stahl, F.; Wydra, K. Transcriptome of silicon-induced resistance against Ralstonia solanacearum in the silicon non-accumulator tomato implicates priming effect. Physiol. Mol. Plant. Pathol. 2011, 75, 83-89. (36) Chain, F.; Côté-Beaulieu, C.; Belzile, F.; Menzies, J. G.; Bélanger, R. R. A comprehensive transcriptomic analysis of the effect of silicon on wheat plants under control and pathogen stress conditions. Mol. Plant-Microbe Interact. 2009, 22, 1323-1330.

(37) Hoagland, D. R; Arnon, D. I. The water culture method for growing plants without soil. Bull.-Calif. Agric. Exp. Stn. 1950, 347, 36-39.

(38) Moldes, C. A.; Medici, L. O.; Abrahão, O. S.; Tsai, S. M.; Azevedo, R. A. Biochemical responses of glyphosate resistant and susceptible soybean plants exposed to glyphosate. Acta Physiol. Plant. 2008, 30, 469-479.

(39) Gomes-Junior, R. A.; Moldes, C. A.; Delite, F. S.; Pompeu, G. B.; Gratão, P. L.; Mazzafera, P.; Lea, P. J.; Azevedo, R. A. Antioxidant metabolism of coffee cell suspension cultures in response to cadmium. Chemosphere 2006, 65, 1330-1337.

(40) Nakano, Y.; Asada, K. Hydrogen peroxide is scavenged by ascorbate-specific peroxidase in spinach chloroplast. Plant Cell Physiol. 1981, 22, 867-880.

(41) Bradford, M. M. A rapid and sensitive method for the quantification of microgram quantities of protein utilizing the principle of protein-dye binding. Anal. Biochem. 1976, 72, 248-254.

(42) Wang, X.; Wei, Z.; Liu, D.; Zhao, G. Effects of $\mathrm{NaCl}$ and silicon on activities of antioxidative enzymes in roots, shoots and leaves of alfalfa. Afr. J. Biotechnol. 2011, 10, 545-549.

(43) Shi, G.; Cai, Q.; Liu, C.; Wu, L. Silicon alleviates cadmium toxicity in peanut plants in relation to cadmium distribution and stimulation of antioxidative enzymes. Plant Growth Regul. 2010, 61, $45-52$.

(44) Liu, J.-J.; Lin, S.-H.; Xu, P.-L.; Wang, X.-J.; Bai, J.-G. Effects of exogenous silicon on the activities of antioxidant enzymes and lipid peroxidation in chilling-stressed cucumber leaves. Agric. Sci. China 2009, 8, 1075-1086.

(45) Feng, J.-P.; Shi, Q.-H.; Wang, X.-F. Effects of exogenous silicon on photosynthetic capacity and antioxidant enzyme activities in chloroplast of cucumber seedlings under excess manganese. Agric. Sci. China 2009, 8, 40-50.

(46) He, Y.; Xiao, H.; Wang, H.; Chen, Y.; Yu, M. Effect of silicon on chilling-induced changes of solutes, antioxidants, and membrane stability in seashore paspalum turfgrass. Acta Physiol. Plant. 2010, 32, 487-494.

(47) Gunes, A.; Inal, A.; Bagci, E. G.; Coban, S. Silicon-mediated changes on some physiological and enzymatic parameters symptomatic of oxidative stress in barley grown in sodic-B toxic soil. J. Plant. Physiol. 2007, 164, 807-811.

(48) Khandekar, S.; Leisner, S. Soluble silicon modulates expression of Arabidopsis thaliana genes involved in copper stress. J. Plant Physiol. 2011, 168, 699-705.

(49) Vertegel, A. A.; Siegel, R. W.; Dordick, J. S. Silica nanoparticle size influences the structure and enzymatic activity of adsorbed lysozyme. Langmuir 2004, 20, 6800-6807.
(50) Slowing, I. I.; Trewyn, B. G.; Lin, V.S-Y. Mesoporous silica nanoparticles for intracellular delivery of membrane-impermeable proteins. J. Am. Chem. Soc. 2007, 129, 8845-8849. 